\title{
Parvovirus Infection and Congenital Leukemia: Is It a Causal or Casual?
}

\author{
Dasrilsyah RA ${ }^{\mathrm{a}}$, Ahmad $\mathrm{S}^{\mathrm{a}}$, Tan $\mathrm{GC}^{\mathrm{b}}$, Lim PS ${ }^{\mathrm{a}}$ \\ ${ }^{a}$ Department of Obstetrics \& Gynaecology, ${ }^{b}$ Department of Pathology, Universiti Kebangsaan Malaysia \\ Medical Center
}

\begin{abstract}
Congenital leukemia is an extremely rare disease but frequently fatal. We report a case of intrauterine death (IUD) secondary to congenital erythroid leukaemia associated with maternal Parvovirus B19 infection. Further research is needed to ascertain the association between maternal Parvovirus B19 infection and congenital leukemia.
\end{abstract}

Keyword: congenital leukemia; parvovirus B19; intrauterine death

\section{INTRODUCTION}

Congenital leukemia is an extremely rare disease but frequently fatal. Its association with trisomy 8 , 19 , and 21 had been well documented. ${ }^{1}$ Other aetiologies include intrauterine insults, exposure radiation during pregnancy and viral infection.

We report a case of intrauterine death (IUD) secondary to congenital erythroid leukaemia associated with maternal Parvovirus B19 infection.

\section{CASE REPORT}

A 34 year-old Gravida 7 Para 2+4 at 30 weeks gestation, was referred for further management of intrauterine death following febrile illness. She had two previous caesarean sections and four first trimester miscarriages.

Her antenatal follow ups were uneventful. She presented with one-day history of reduced fetal movement and fever associated with chills and rigors. There was no symptom suggestive of upper respiratory tract, lower urinary tract infection or dengue fever. She did not experience any rash or arthralgia as well.

Upon arrival, she was not pale. She had low-grade fever, but other vital signs were normal. Cardiovascular and respiratory examination was unremarkable. Abdominal examination revealed a

Corresponding author:

Assoc Prof Dr Pei Shan Lim

Department of O\&G, Faculty of Medicine

Universiti Kebangsaan Malaysia Medical Center

Jalan Yaakob Latif,

56000 Cheras, Kuala Lumpur, Malaysia

Tel: $+603-91455950$

Facsimile: $+603-91456672$

E-mail address: peishan9900@yahoo.com/

pslim@ppukm.ukm.edu.my
28 weeks size uterus. The fetus was in longitudinal lie with cephalic presentation. Ultrasound scan confirmed the diagnosis of an IUD with no hydropic features. The couple was counselled regarding the diagnosis and bereavement counselling was given. She had an uneventful delivery following combination of mechanical and prostaglandin induction. She delivered a baby girl with birth weight of $1.33 \mathrm{~kg}$. There was no dysmorphic features or skin lesion noted. Post mortem consent was obtained.

Upon follow up review, her blood investigation was negative for anticardiolipin antibody, anti nuclear antibody, rheumatoid factor and TORCHES screening. The placental swab culture \& sensitivity revealed no growth of pathogen. However, maternal Parvovirus B19 Ig M was positive.

Histopathological examination of the placenta showed that most of the fetal blood vessels were infiltrated by atypical erythroblast and myeloid precursor cells which were positive for both glycophorin and myeloperoxidase immunohistochemical. There was extensive neutrophilic infiltration within the chorion and amnion. The autopsy revealed no evidence of congenital malformation or cardiac abnormality. There was hepatosplenomegaly. The lung, liver and spleen were infiltrated extensively by atypical erythroblasts displaying fairly uniform, round to wrinkled hyperchromatic nuclei with granular eosinophilic cytoplasm.

Some have bizarre irregular nuclei and prominent nucleoli. Immunohistochemically, these malignant cells are diffusely positive for glycophorin and occasional myeloblasts are seen as supported by myeloperoxidase (MPO) positivity (Figure 1). 
Diagnosis of acute erythroid leukemia infiltrating the placenta, lung, liver and spleen was made. In view of previous four miscarriages with current diagnosis of congenital leukemia, parental blood were sent for cytogenetic study which revealed no chromosomal abnormality detected.
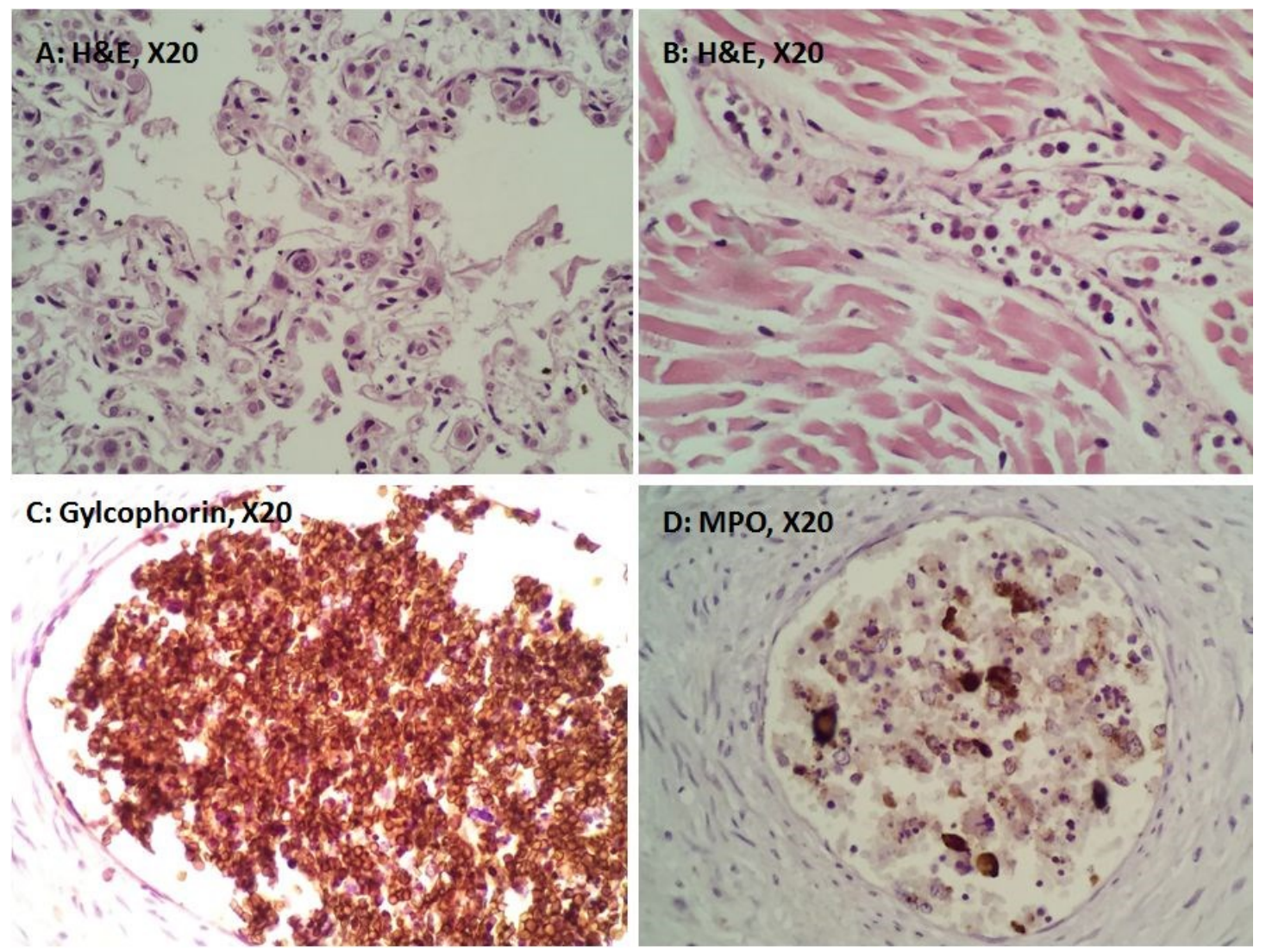

Figure 1. A) Blast cells are seen in the blood vessels within the lung. B) Blast cells are seen in the blood vessels within the myocardium. Immunohistochemically, the blast cells are immunoreactive toward glycophorin (C) and some toward myeloperoxidase (D).

\section{DISCUSSION}

Congenital leukemia usually presents at birth or within initial few months of life. Male infants were predominant. ${ }^{2}$ Recognized clinical manifestations include petechiae, nodular skin infiltrations, hepato -splenomegaly, adenopathy, fever and anaemia. ${ }^{2}$ Infections such as toxoplasmosis, cytomegalovirus, syphilis and HIV may contribute to similar clinical presentation.

Majority of the reported cases have acute non lymphoblastic type i.e. myeloid phenotype. Acute erythroid leukemia is rare and only accounts for less than $5 \%$ of acute myeloid leukemia. ${ }^{3}$ It is an aggressive disease with poor outcome. It commonly affects adult population above 50 years old with male predominance. ${ }^{3}$ Nonetheless, congenital erythroid leukemias had also been reported. ${ }^{1,4}$ These cases were live birth, presented soon after birth but with fatal outcome. The current case presented as an IUD. The diagnosis could have been missed if postmortem was not performed.

Upon investigating the cause of IUD, maternal serum was found to be positive for parvovirus B19 IgM suggesting recent infection. Parvovirus B19 is a common infection in human worldwide. Erythroid progenitor cell of the bone marrow is the main target of parvovirus B19. Susceptibility to parvovirus B19 in the erythroid lineage was noted to increase with differentiation. ${ }^{5}$

Heegaard et al and Savasan et al. had reported cases of parvovirus B19 induced pancytopenia prior to acute leukemia. ${ }^{6,7}$ Could in-utero parvovirus B19 infection contributed to the development of congenital leukemia in the present case? Greaves has postulated that infection plays role in childhood leukemia ${ }^{8}$, while host immune response to infection had been hypothesized as an important factor in the pathogenesis of parvovirus B19 associated acute leukemia. ${ }^{9}$ Up-regulation of granulocytemacrophage colony stimulating factor (GM-CSF) in parvovirus B19 infection was suggested to be partly responsible for the conversion of pre-leukemic clones to an overt leukemia. ${ }^{9}$ From acute parvovirus infection to development of leukemia, Savasan et al. and Heegaard et al. reported 9 weeks and 5 months, respectively. IgM normally appears within 
10-14 days after inoculation while IgG will appear few days later. ${ }^{10}$ Maternal parvovirus B19 IgG was negative in present case suggested that the infection might have occurred within 2-3 weeks prior to fetal death. Hence, the parvovirus infection might not have contribution to the development of the congenital leukemia.

However, parvovirus B19 is known to be associated with fetal anaemia, fetal hydrops, and fetal demise. The short life span of fetal red cells and the rapidly expanding red cell volume have made the fetus vulnerable to B19 infection particularly in primary infection due of lack of maternal antibody protection. Takahaski demonstrated that the B19 virus replicated efficiently in fresh leukemic cells in vitro. ${ }^{11}$ Hence, concurrent parvovirus infection with congenital leukemia could have contributed partly to this fetal demise, though B19-DNA test was not performed during the autopsy.

In-utero parvovirus infection may potentially lead to congenital leukemia. Testing for parvovirus B19 fetal infection and cytogenetic study for aneuploidies during the autopsy, if it was done, would have assisted us in analysing this association. Hence, it would be interesting to investigate for in-utero parvovirus B19 exposure or to study parvovirus B19-DNA in leukemia cells in future cases of congenital leukemia.

\section{Conflict of Interest}

The authors declare no conflict of interest.

\section{Acknowledgement}

We would like to thank Prof Dr Chooi Fun Leong for assisting us in examining the autopsy specimens.

\section{REFERENCES}

1. Haught EAS, Johnson MC, Witt PD. Congenital erythroleukemia presenting as a congenital infantile hemangioma. Plastic and Reconstructive Surgery 2007; 119:70e-72e.

2. Bernhard WG, Gore I, Kilby RA. Congenital leukemia. Blood 1951;6:990-1001.

3. Mihova D, Zhang L. Acute erythroid leukemia: A Review. N Am J Med Sci 2012; 5:110-118.

4. Lazure T, Beauchamp A, Croisille L, Ferlicot S, Feneux D, Fabre M. Congenital anerythremic erythroleukemia presenting as hepatic failure. Archives of pathology \& laboratory medicine 2003; 127:1362-5.

5. Takeshi T, Ozawa K, Takahashi K, Asano S, Takaku F. Susceptibility of human erythropoietic cells to B19 Parvovirus in vitro increases with differentiation. Blood 1990; 75:603-10.

6. Heegaard ED, Madsen HO, Schmiegelow K. Transient pancytopenia preceding acute lymphoblastic leukaemia (pre-ALL) precipitated by parvovirus B19. British Journal of Haematology 2001; 11:810-3.
7. Savașan, S, Özdeïr Ö. Parvovirus B19 infection and acute lymphoblastic leukaemia. British journal of haematology 2003; 120:168-9.

8. Greaves MF. Aetiology of acute leukaemia. Lancet 1997; 349:344-9.

9. Kerr JR, Barah F, Cunniffe VS, et al. Association of acute parvovirus B19 infection with new onset of acute lymphoblastic and myeloblastic leukemia. J Clin Pathol 2003; 56:873-5.

10. Crane J, Mundle W, Boucoiran I, et al. Parvovirus B19 infection in pregnancy. J Obstet Gynaecol Canada 2014; 36:1107-16.

11. Takahashi T, Ozawa K, Mitani K, Miyazono K, Asano S, Takaku F. B19 parvovirus replicates in erythroid leukemic cells in vitro. Journal of Infectious Diseases 1989; 160: 548-9. 
